\title{
Automatic Guided Vehicles Introduction Impacts to Roll-On/ Roll-Off Terminals: Simulation and Cost Model Analysis
}

\author{
Sang Hyung Park $\mathbb{D}^{1},{ }^{1}$ Jeho Hwang $\mathbb{D}^{2},{ }^{2}$ Sohyun Yun $\mathbb{D}^{1},{ }^{1}$ and Sihyun Kim $\mathbb{D}^{2}$ \\ ${ }^{1}$ KMOU-KMI Cooperative Course, Korea Maritime and Ocean University, Busan 49112, Republic of Korea \\ ${ }^{2}$ Department of Logistics, Korea Maritime and Ocean University, Busan 49112, Republic of Korea \\ Correspondence should be addressed to Sihyun Kim; sihyunkim@kmou.ac.kr
}

Received 30 August 2021; Revised 4 January 2022; Accepted 17 January 2022; Published 30 January 2022

Academic Editor: Michele Simoni

Copyright (C) 2022 Sang Hyung Park et al. This is an open access article distributed under the Creative Commons Attribution License, which permits unrestricted use, distribution, and reproduction in any medium, provided the original work is properly cited.

\begin{abstract}
Automatic guided vehicles (AGVs) have been successfully applied to cargo terminals to reduce operating costs and improve productivity. However, the focus was on container terminal operations. Ports with roll-on/roll-off (RORO) terminals still heavily depend on human resources for the loading/unloading processes. Work operations are affected by human errors and safety issues. In particular, terminals where vehicles cannot be stacked pressure workers to handle cargo more rapidly, which induces more errors. In this study, we propose automating RORO terminal operations by using AGVs. We assessed the impact of AGVs on the productivity, cost efficiency, and environment. A series of simulation models was developed on the basis of the current loading system at an actual port to test the impact of AGVs. Then, we developed a cost model to analyze the economic benefit of AGVs compared with the current loading system. The environmental benefits were also analyzed. Results revealed that a system using 29 AGVs matched the productivity of the current loading system, and using more AGVs increased the productivity. For a given productivity level, the total operating cost of the AGV system was three times less than that of the current system over a 15-year period. The AGV system also showed great potential for improving the environmental friendliness of terminal operations. This is the first study to propose automating RORO terminal operations to improve productivity and sustainability through AGV technology rather than human factors. AGVs are expected to become a good option in the future to address labor shortages and the "untact" era.
\end{abstract}

\section{Introduction}

Seaports are one of the most important elements of a country's economy and play an important role in international commerce and trade [1]. They not only handle commercial cargo, but also are centers of economic activity [2]. Accordingly, port administrations are under great pressure to increase their productivity and compete with other ports around the world [3]. The increased competition in the port industry has encouraged the development of automated terminals to reduce operating costs and improve productivity, safety, and environmental sustainability [4]. The greatest proponents of automation in the port domain are container terminals [5]. In contrast, roll-on/roll-off (RORO) terminals are still heavily dependent on human resources because drivers have to move vehicles one by one.
Furthermore, vehicles in the terminal cannot be stacked, so workers are under pressure to complete tasks quickly in the given time [6]. This had led to human errors and safety issues $[7,8]$. In addition, the movement of thousands of vehicles inevitably produces a large amount of $\mathrm{CO}_{2}$ emissions. This can be a problem because maritime sectors have been requested to find green solutions in the face of increasingly stringent environmental regulations [9].

A significant element of automated terminals is AGVs. Automated container terminals using AGVs have seen many benefits such as reduced costs and improved productivity, safety, and environment [5]. The AGV system was not considered in the RORO terminal before as navigating AGVs in car carriers may be more complex than operating an AGV just on a flat surface due to their complex layout with collapsible decks and steep ramp. First-generation 
AGVs were designed to navigate according to line-following principles using technologies such as embedded guide wires, paint stripes, magnetic tape, and laser guidance. Since then, the advent of new technologies has transformed how AGVs navigate and to what they can be applied. The development of intelligent autonomous vehicles (IAVs) and automated lifting vehicles (ALVs) has alleviated the limitations of previous AGVs that had to follow a fixed track [10, 11]. IAVs can pick up/drop off cargo by themselves and can navigate without following any fixed track by using a wireless link with an intelligent virtual real-time simulator. Research has been increasing on the subject of unmanned vehicle navigation. In particular, many studies have focused on the development of unmanned forklifts that can navigate without the line-following principle $[12,13]$. The French start-up company Stanley Robotics recently developed an AGV capable of parking vehicles at airports [14]. Their AGV uses Global Navigation Satellite System, a camera, and LiDAR-based simultaneous localization and mapping technologies for pathfinding, which is potentially applicable to any environment. Therefore, such AGV system can now be applicable in the RORO terminal to load the cars from the yard to the RORO ship for the automation.

The pure car and truck carrier (PCTC) currently occupies most of the RORO ship market. The loading process of a PCTC starts with each driver taking a vehicle onto the ship via the stern ramp [15]. Each driver has to wait $5 \mathrm{~s}$ before departing the yard to avoid colliding with the previous vehicle. Once drivers reach the parking lot, they leave the vehicle and head to the shuttle van. After the van collects 8-10 drivers, it drives back to the yard for the drivers to bring the other vehicles one by one. Employing AGVs changes several aspects of the current operation. First, the main resource for the loading process becomes the $\mathrm{AGV}$. In other words, the human intervention in the loading process is reduced, and the number of resources can be increased and limited at any time as desired. Second, AGVs move around the terminal individually. While drivers have to wait for the shuttle van to fill up before they can leave the ship, AGVs can go directly to the yard to pick up the next vehicle. This eliminates the waiting time for each batch of drivers, and AGVs that have begun the loading process do not need to wait $5 \mathrm{~s}$ to avoid simultaneous departures. Additionally, the current loading system uses vehicles powered by fossil fuels for shipping cargo and transportation. In contrast, AGVs are powered by electricity, which should reduce $\mathrm{CO}_{2}$ emissions.

We propose automating RORO terminal operations to improve port productivity and sustainability. In this study, we were focused on demonstrating the potential benefits from introducing them to current RORO terminals. We investigated the effect of using AGVs on the operation of RORO terminals with regard to productivity, cost efficiency, and environmental impact.

The contribution of this study lies as follows. First, a detailed simulation model for the actual RORO terminal shipping process is developed. Second, this study proposes automating RORO terminal operation with AGV technology. Third, a detailed cost model is developed to estimate the total operational cost with different parameters for the AGVs loading system and the current loading system (i.e., car and van). Fourth, environmental impact from the operation of the vehicle in the terminal is evaluated.

The current loading system has been highly dependent on drivers. Therefore, developing the automated loading system using AGVs in the RORO terminal could significantly improve the current operating system and address the labor shortage.

The rest of the paper is structured as follows. Section 2 reviews relevant materials and methods on RORO terminal productivity and the development of simulation models using Arena software. In the following section, we investigated the port performance with different numbers of AGVs to identify the optimal number of AGVs, followed by the results of data analysis from an actual terminal. Section 3 presents the simulation results and the cost model analysis on the overall benefits of the AGV loading system and environmental impact. Section 4 gives the conclusions.

\section{Materials and Methods}

2.1. Relevant Studies on RORO Terminal Productivity. In the last few decades, few studies have been carried out on the operation of RORO terminals compared with other terminals so the relevant literature is scarce. However, the main factor for the RORO terminal operation is human resources. This review focuses on literature relevant to RORO terminal productivity from two different perspectives: worker productivity and simulation studies.

2.1.1. Worker Productivity. Workers are the main influence on the productivity of RORO terminals $[16,17]$. However, the human resources for RORO terminal operation have limited capacity for further improvement, which reiterates the necessity of automation. There are many ways to improve worker productivity, and they are interrelated. Many studies have focused on the link between working hours and productivity [18-20]. Most revealed that the working hours are not proportional to the work productivity. Especially for skilled jobs such as stevedores, ensuring an effective working time is important for reducing the onset of fatigue, which can affect productivity. A RORO terminal typically has a $9 \mathrm{~h}$ workday with six break times per day. However, many RORO terminals are under competitive pressure with an increasingly global maritime trade $[3,21]$, which has resulted in a lot of overtime. This has inevitably led to human errors during terminal operations $[7,8]$. More workers can be hired to reduce human errors, but labor overuse usually greatly increases costs and inefficiency [22].

Many studies have also noted concerns over worker safety and health at ports [23, 24]. Major health concerns include fatigue, back pain, and headaches due to poor air conditions, the noisy environment, and lack of facilities [25]. Such occupational health and safety issues are a major reason for the reduced productivity at ports [26, 27].

Over the past few decades, automation and robotics have been promoted as a solution to the aforementioned issues [28-30]. Many industrial sites have improved human factors 
and productivity through automation. A large volume of literature is available on automation in container terminals, but studies on automating RORO terminals are scarce. To the best of our knowledge, we are the first to suggest automating the loading system as a solution to improving the productivity of RORO terminals, rather than focusing on worker productivity. The following subsection introduces simulation studies to measure the productivity of the RORO terminal.

2.1.2. Simulation Studies. As seen in the above section, the productivity of the RORO terminal highly depends on the worker's productivity, and it is difficult to be measured. So many researchers have experimented with simulation studies. In this subsection, relevant studies on the RORO terminal simulation are introduced.

Bottlenecks can have a significant impact on the performance of a port. To ensure the smooth flow of cargo, bottlenecks should be identified in advance and optimized to reduce congestion. This not only improves port productivity, but also prevents overuse of resources and overinvestment. Simulation approaches are generally used to optimize terminal operation and determine the optimum levels of investment and resources.

Demirci [31] used the simulation program AweSim to identify operational bottlenecks for Trabzon Port in Turkey. The simulation model was constructed on the basis of realistic data related to port operation. In the full-capacity situation, loading/discharging vehicles were investigated as a bottleneck, and the number of vehicles was optimized under economic constraints. Adding vehicles improved the port performance and reduced the ship turnaround time by 8 days. The strength of the simulation model at analyzing the port performance was demonstrated.

Keceli et al. [21] used the software Arena to develop a simulation model for RORO terminal operation. They identified waiting area 3 as a bottleneck and suggested that it should be enlarged. The simulation results demonstrated the usefulness of the simulation model and its potential applicability to other RORO terminals. The authors also discussed the importance of building a simulation model to predict the effects of any planned changes.

Muravev et al. [32] compared two software programs for discrete-event simulation (DES) modelling. They modelled the operation of a RORO terminal with Arena and AnyLogic independently. Their results showed that the two software programs were practically similar. Small differences in the results were attributed to random numbers created by the different mechanisms of the programs. Experimental results indicated that Arena is suitable for simulation modelling of RORO terminals to optimize the system operation and identify failures in advance.

RORO terminal is the work site heavily reliant on workers' performance during the loading process. As can be seen from the review above, the reviewed simulation studies have addressed the general operating system, but the details of the loading system in the terminal were not studied. Also, past literature did not consider automating the operation in
RORO terminal. Therefore, in this study, we developed a series of simulation models to test the loading system in the RORO terminal and suggest the automation with AGVs for the first time.

\subsection{Simulation Model Development}

2.2.1. Target Port and Ship. As a case study, we considered port A, which is the largest automobile import-export gateway in South Korea. Figure 1 shows the layout of port A. Glovis Splendor is a PCTC, which is one of the most widely utilized vehicle carriers on major deep-sea trade routes with a carrying capacity of $7353 \mathrm{R} / \mathrm{T}$. $\mathrm{R} / \mathrm{T}$ is the largest number of standard-sized vehicles that Ro-Ro ships can load motivated from RT43, a 1966 Toyota Corolla [15]. The parking space in the yard was calculated as $6.39 \mathrm{~m}^{2}$ per unit for 7353 vehicles considering clearance space. The actual parking space can differ depending on the vehicle type. However, we considered the standard vehicle size to calculate the largest number of vehicles that can be loaded on a ship, which is also called the nominal vehicle carrying capacity [33]. The parking space in the yard was calculated for 7352 vehicles and divided into blocks a-d.

2.2.2. Arrival Distribution. The arrival distribution represents the arrival of entities as a discrete set of points. Because the 7352 vehicles in the yard are at different positions, the probabilities for arrival at the next point are different between the first and last vehicles. However, in most cases, the vehicles are parked in the yard in rectangular blocks, so the minimum and maximum probabilities for the first and last vehicles to arrive at the next point are clearly defined. Therefore, we used a triangular distribution to define the transfer of 7352 vehicles from the yard to the vessel.

2.2.3. Vehicle Speed and Loading Strategy. The vehicle speed was set in compliance with the Hyundai Glovis transportation and handling manual. Table 1 indicates that each section of the port has different speed limits, so different speeds were applied to each section. The AGVs had a maximum speed that was less than the speed limit, so we allowed them to operate at maximum speed in every section. We also reduced the safe following distance for AGVs considering their speed. The loading strategy was considered to reduce the queueing bottleneck; vehicles nearest to the vessel were prioritized for loading first.

2.2.4. Scenario Development. A simulation model can be used to depict operation concepts that are not used in a real port. We developed scenarios to demonstrate improvements to the loading system. Two scenarios were considered with different path plans for the AGV loading system. In scenario 1 , vehicles follow the same path as the current loading system: one-way movement within the external ramp. If vehicles entering from different sides meet at the ramp, the first one to enter the ramp takes precedence. Scenario 2 allows two-way movement, which means that vehicles can 


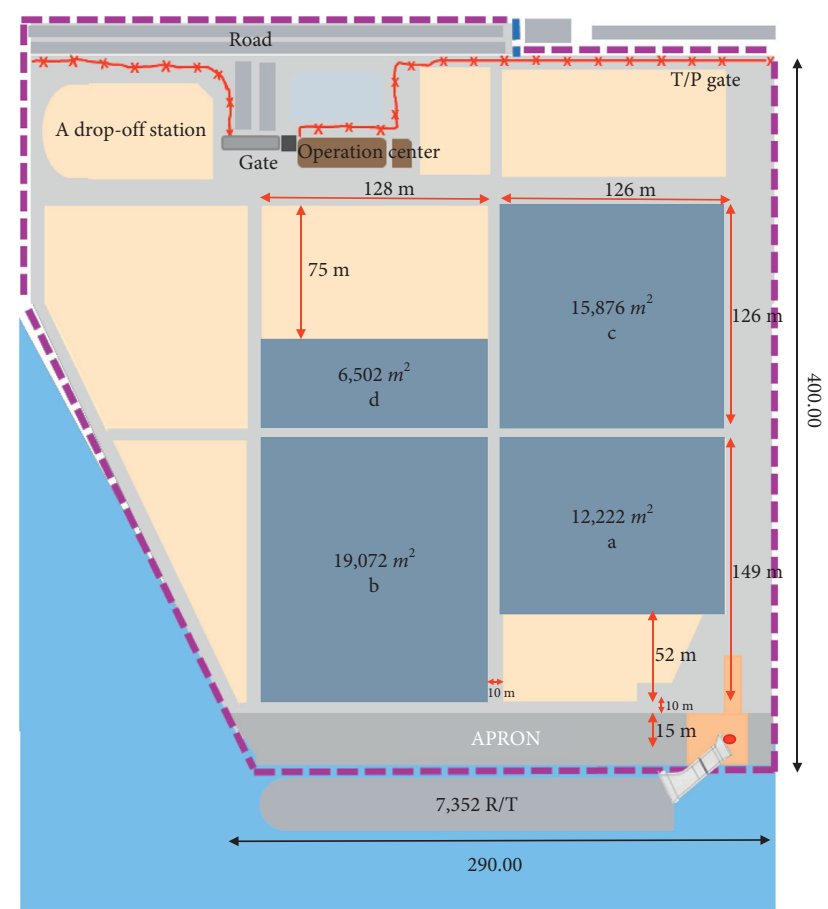

FIGURE 1: Parking space for vehicles in the yard of port (A) (source: author).

TABLE 1: Vehicle speed and safe following distance in the simulation model.

\begin{tabular}{lccc}
\hline & Yard $(\mathrm{km} / \mathrm{h})$ & External ramp $(\mathrm{km} / \mathrm{h})$ & Safe distance $(\mathrm{m})$ \\
\hline Drivers & $21.25-25.0$ & $6.8-8.0$ & 15 \\
AGVs & 10 & 10 & 6 \\
\hline
\end{tabular}

bypass each other on the ramp. Therefore, three different loading systems were compared: the current loading system, AGV loading system scenario 1, and AGV loading system scenario 2 .

2.3. Arena Simulation Modelling. Arena is a DES software that models real-world systems with a stochastic nature. Arena is a good option for simulating terminal operation. Numerous studies have used Arena to model container terminals because it can be used to analyze complex port systems [34, 35]. Although few studies have considered RORO terminals, most also used Arena for simulations $[21,32]$. Arena simplifies the model building and overcomes mathematical limitations [36]. By running simulations at slow speed, the logic of the process can be checked, and discrete points where a large queue occurs can be identified [37]. In this study, we used Arena 14.0 for building, testing, and analyzing the simulation models. Because we were focused on evaluating the terminal performance, we used the module function "tnow" to measure the loading time.

2.3.1. Simulation Assumptions. We made the following assumptions to reduce unnecessary details and compare the simulation models under the same conditions: (i) The loading/unloading places are identical, and the loading cargos are the same assuming that all 7352 standard size cars are loaded

(ii) The surfaces of deck pillars are not considered because the space between pillars is large, and their surfaces are small

(iii) The vehicles depart from the yard to the ship at the same time

(iv) A specific stowage plan considering the balance of the ship is not detailed

2.3.2. Arena Simulation Models. Two simulation models were developed and tested in Arena; the current loading system and the AGV loading system scenarios 1 and 2 . Before testing the simulation model of the AGV loading system, we confirmed the validation against the real data from the actual loading system. Because drivers are under pressure to complete the tasks quickly, the actual loading process is carried out at speeds beyond the speed limit; thus, we used our simulation model to calculate the standard loading time as specified in the manual. According to the real data from the Pyeongtaek Port, the average vehicle loads recorded 100 per hour. With an average vehicle loads of 95 per hour, we reported the result of the simulation's confidence interval at the 95 percent $(=0.05)$ confidence level to assure results validity. The result shows that the simulation reproducing current loading system is valid and accurate. It hence can be used to investigate the impact of AGV loading system.

The CREATE module is the starting point for entities in a simulation. The DISPOSE module is the entity's ending point. The ASSIGN module allows you to assign values to entities including entity type, variables, and attributes. The BATCH module can group entities permanently or temporarily, and temporary batched entities must be split later using the SEPARTE module. The HOLD module places an entity in a queue to wait for a signal or a specified condition.

Figure 2 shows the simulation model for the current loading system. The vehicles' arrival to the yard was represented by the CREATE module, which is located at the top of the figure as the first module. The DECIDE module divided the vehicles among the yard blocks a-d. The SEIZE module restricted the number of drivers. Since each driver has to wait for $5 \mathrm{~s}$ before departing the yard to avoid colliding with the previous vehicle. The PROCESS module, which is located on the very right side in the figure, was used. The BATCH module simulated the collection of drivers by the shuttle van. After drivers left the van in the SEPARATE module, they started a new loading process with the RELEASE module until all vehicles were loaded. Figure 3 shows the simulation model for the AGV loading system. The $5 \mathrm{~s}$ rule was only implemented for the first group of AGVs. The BATCH module was removed because AGVs went back to the yard individually. The SEIZE module was used to control the number of AGVs for the sensitivity analysis. 


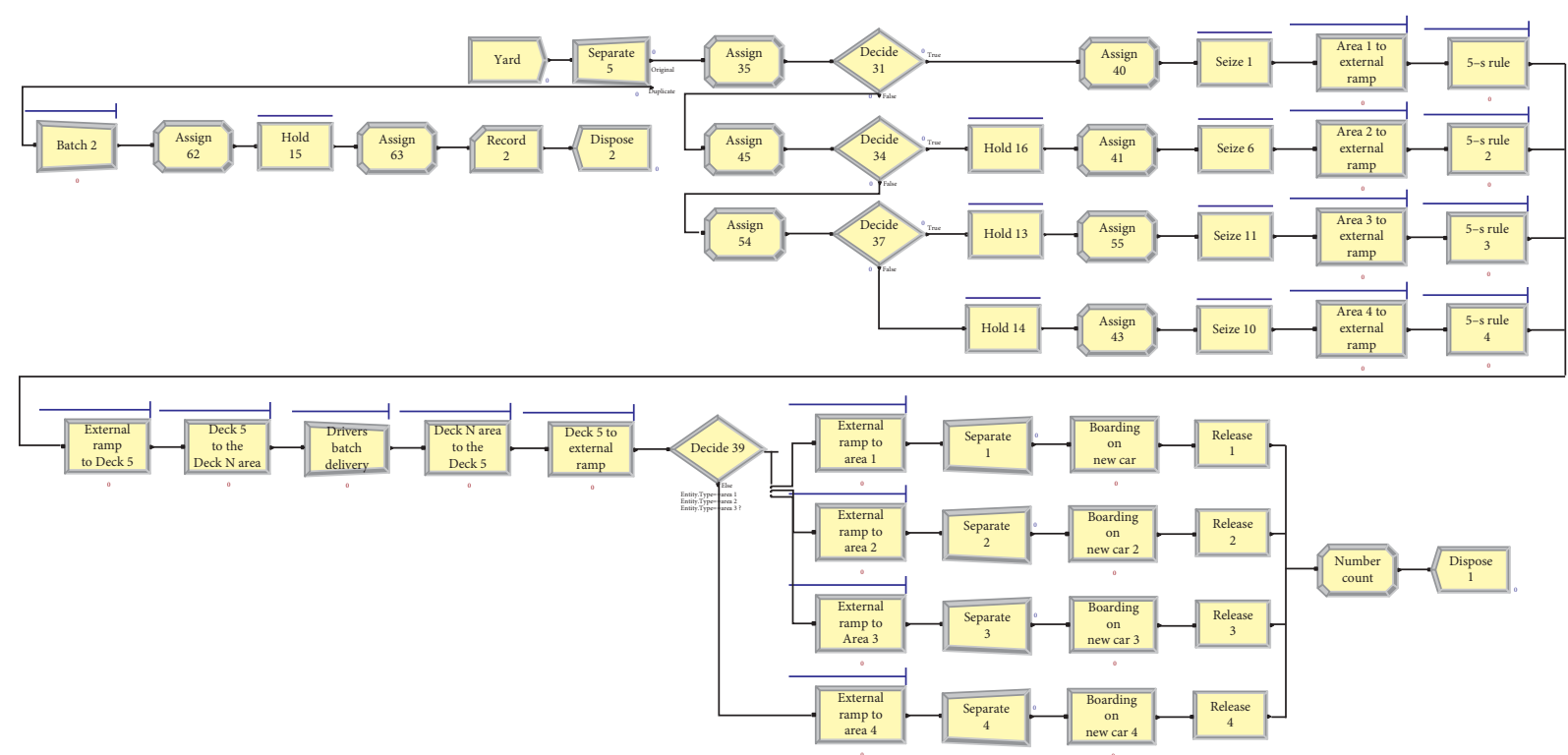

FIgURE 2: Simulation model of the current loading system in Arena (source: author).

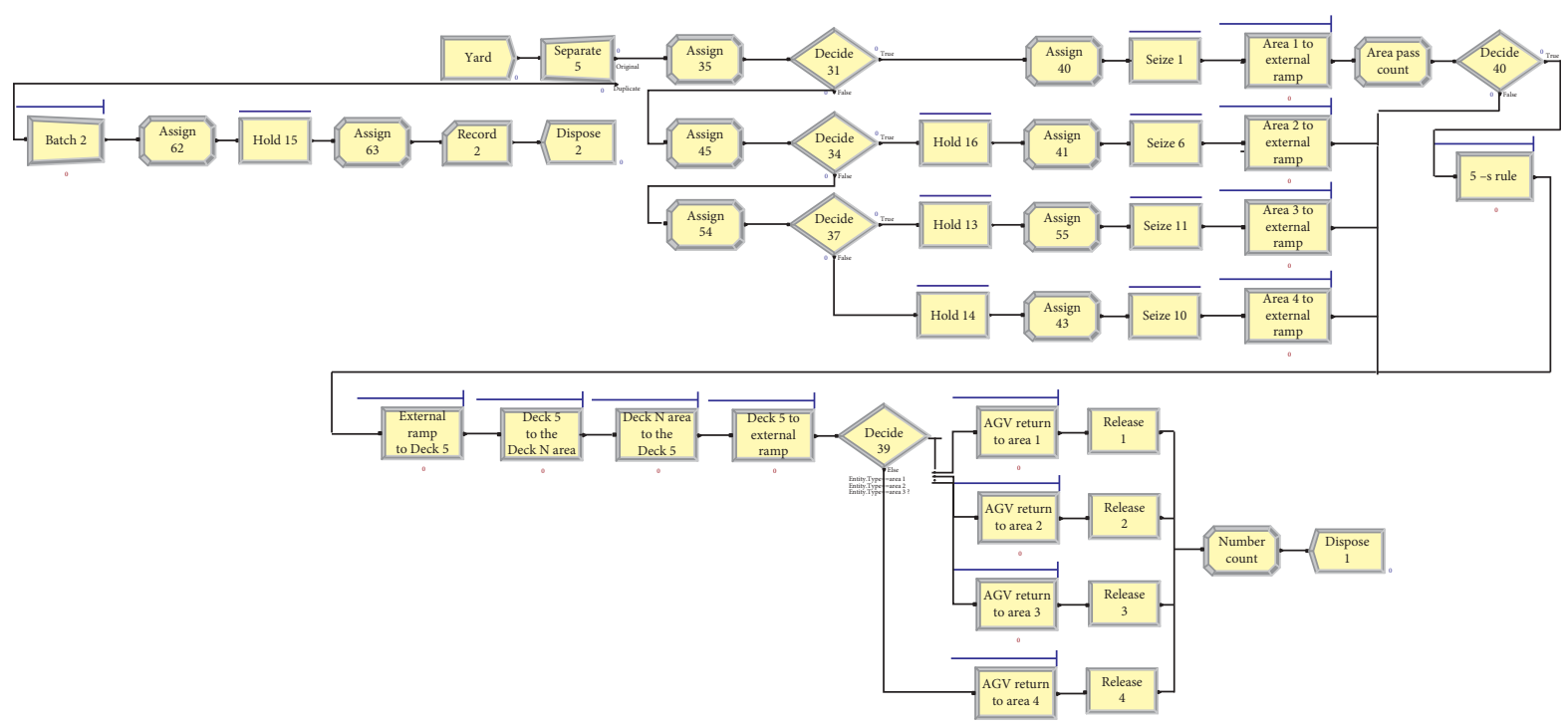

FIGURE 3: Simulation model of the AGV loading system in Arena (source: author).

2.4. Sensitivity Analysis. As discussed previously, port operation with vehicles involves congestion at certain points. Increasing the number of resources will not continuously improve the productivity. Thus, sensitivity analyses help with properly assessing the impact of key variables. This is done by varying the value of a particular variable while fixing the value of other variables. Park et al. [15] tested several AGVs using mainly inside car carrier. Increasing the number of AGVs reduced the total loading time, but it also increased the waiting time in the bottleneck. The result deviated slightly from the result in this study as the previous study did not address the AGVs traffic at the yard. In addition, the previous study did not detail the impacts of introduction such as the economic and environmental benefits.
Nguyen and Kim [38] performed a sensitivity analysis on the number of ALVs and buffer capacity at a port. Their results showed that increasing the number of ALVs improved port productivity and reduced the total delay in quality control operations. In contrast, the buffer size had a larger effect with fewer ALV. They used mathematical models such as heuristic algorithms for optimization and commented that simulation experiments could be used to solve problems in more dynamic environments. In addition, they only addressed the dispatch of ALVs without integrated scheduling.

Pjevčević et al. [39] used Arena to develop a simulation model of the container handling process and investigated the effects of dispatching rules and the number of AGVs. Their results showed that the number of served 
containers increased with the number of AGVs. However, increasing the number of AGVs also decreased the active rate of AGVs. This study indicated the importance of appropriately choosing the number of AGVs and dispatching rules. They did not consider the economic benefit of AGVs because their focus was on the dispatching rule and number of AGVs.

Kavakeb et al. [40] used the software Flexsim CT to develop a simulation model for a container terminal in Europe. They then performed a sensitivity analysis on the buffer size and number of IAVs. They developed a cost model to estimate the total cost-benefit of using IAVs. Their results showed that IAVs can significantly improve port performance compared with trucks despite their slower speed and had a much lower total operating cost. They also used an advanced vehicle dispatching strategy to improve the port performance further. However, although the IAV used in their study is environmentally friendly, they did not investigate the environmental benefits.

The aforementioned literature demonstrates the usefulness of sensitivity analysis for evaluating the impact of AGVs on terminal operation. In our study, we performed a sensitivity analysis to optimize the number of AGVs, and we investigated the economic and environmental benefits of the optimized AGV loading system compared with those of the current loading system.

\section{Results and Discussion}

3.1. Simulation Results. The results of the simulation models were compared for the current loading system, AGV loading system scenario 1, and AGV loading system scenario 2. For the AGV loading systems, the number of vehicles varied from 10 to the maximum number.

3.1.1. Current Loading System. Figure 4 shows the simulation results for the current loading system. The longest waiting time was attributed to the batch delivery process, where drivers were collected by the shuttle van. The secondlongest waiting time was attributed to the $5 \mathrm{~s}$ rule, which was applied to all vehicles to avoid collision with preceding vehicles. The total loading time was $93,099.70 \mathrm{~s}$, which implies that the actual work time charge can be almost three days. As mentioned in Section 2.3.2, these results are similar to the actual data of port A.

Based on the performance of the current loading system, the AGV loading system had a target time of 93,099.70 s to complete the loading process. To investigate the impact of AGVs on port A, a sensitivity analysis was performed, where the number of AGVs varied from 10 to the maximum. The maximum number of AGVs that affected the loading time was 40 . Table 2 presents the results of AGV loading system scenario 1 . The simulation results are reported the same way as in Figure 4 and we tested the use of 10-40 AGVs. The average waiting times within the external ramp and the total loading times were compared. For scenario 1, the minimum number of AGVs to meet the target performance was 31 .
Above the maximum number of 40 AGVs, the productivity remained the same, whereas the waiting time within the external ramp increased.

3.1.2. AGV Loading System Scenario 2: Two-Way Movement. In the current loading system, vehicles do not pass each other on a ramp, even though the ramp has enough space for two vehicles. This is to avoid collisions between vehicles travelling fast. Moreover, vehicles returning to the yard and entering the ship are less likely to meet because drivers are sent back to the yard by a shuttle van. However, the slower speed of AGVs caused a large queue to form within the external ramp with AGV loading system scenario 1. Thus, we developed an alternative path plan for AGVs to reduce the congestion. Because advanced sensors allow autonomous vehicles to detect objects much faster and more accurately than human drivers can [41], AGVs should be able to bypass each other on the ramp. In addition, the maximum speed of the AGVs in this study was less than $10 \mathrm{~km} / \mathrm{h}$, so collisions are less likely to happen. Therefore, in scenario 2, vehicles were allowed to cross within the ramp. This was implemented in the simulation model by doubling the resources used for the external ramp. The results were retrieved in the same way as in scenario 1 . By reducing the average waiting time within the ramp, the maximum number of AGVs that could be employed in scenario 2 was increased to 70 . The difference between the two scenarios was large when more AGVs are used. In scenario 2, with $29 \mathrm{AGVs}$, the total loading time was $93107 \mathrm{~s}$ reaching the performance of the current loading system revealed in Subsection 3.1.1, and its average waiting time was $1.914 \mathrm{~s}$. As can be seen in Table 2, in scenario 1, the use of 31 reached the performance of the current loading system, and its average time was $11.852 \mathrm{~s}$, which was $9.938 \mathrm{~s}$ larger than scenario 2 . The maximum use of scenario 1 was 40 AGVs, and its loading time was $87394 \mathrm{~s}$ with $54.296 \mathrm{~s}$ average waiting time. The maximum use of scenario 2 was 70 AGVs, and its loading time was $44869 \mathrm{~s}$ with $55.365 \mathrm{~s}$ average waiting time. This implies that scenario 2 can achieve much higher productivity with lower waiting time. Figure 5 compares the results of scenarios 1 and 2. Scenario 2 increased the overall productivity and reduced the minimum number of AGVs to meet the target performance to 29 . The average waiting time at the ramp was much less than that in scenario 1 , which indicates less congestion. The results of scenario 2 demonstrate that the congestion caused by the slower speed of AGVs can be solved by applying a suitable path plan.

The simulation result from either scenario shows that the use of AGV can reduce the work time charge less than the current loading system when used more than 29 AGVs. In particular, the use of the maximum number of AGVs in scenario 2 showed the possibility to reduce the working hour time to less than one day. Indeed, the impact of adopting AGVs is larger in terms of cost efficacy. Therefore, in the following subsection, we compare AGVs and current loading system based the on the total capital and operational cost in a 15-year periods. 
Replications: 20 Time Units: Seconds

\begin{tabular}{|c|c|c|c|c|c|c|}
\hline \multicolumn{7}{|l|}{ Queue } \\
\hline \multicolumn{7}{|l|}{ Time } \\
\hline Waiting Time & Average & Half Width & $\begin{array}{r}\text { Minimum } \\
\text { Average }\end{array}$ & $\begin{array}{r}\text { Maximum } \\
\text { Average }\end{array}$ & $\begin{array}{r}\text { Minimum } \\
\text { Value }\end{array}$ & $\begin{array}{r}\text { Maximum } \\
\text { Value }\end{array}$ \\
\hline 5 seconds rule 2.Queue & 10.3593 & 0.09 & 9.9921 & 10.7940 & 0.00 & 99.79 \\
\hline 5 seconds rule 3.Queue & 11.3196 & 0.07 & 11.0879 & 11.6991 & 0.00 & 101.20 \\
\hline 5 seconds rule 4.Queue & 11.0598 & 0.13 & 10.5566 & 11.5389 & 0.00 & 98.5915 \\
\hline 5 seconds rule.Queue & 11.8209 & 0.06 & 11.6117 & 12.0115 & 0.00 & 101.94 \\
\hline area 1 to External ramp.Queue & 0.00 & 0.00 & 0.00 & 0.00 & 0.00 & 0.00 \\
\hline area 2 to External ramp.Queue & 0.00 & 0.00 & 0.00 & 0.00 & 0.00 & 0.00 \\
\hline area 3 to External ramp.Queue & 0.00 & 0.00 & 0.00 & 0.00 & 0.00 & 0.00 \\
\hline area 4 to External ramp.Queue & 0.00 & 0.00 & 0.00 & 0.00 & 0.00 & 0.00 \\
\hline Batch 2.Queue & 0.00 & 0.00 & 0.00 & 0.00 & 0.00 & 0.00 \\
\hline Deck 5 to External ramp.Queue & 1.0438 & 0.07 & 0.8343 & 1.4704 & 0.00 & 19.1323 \\
\hline $\begin{array}{l}\text { Deck } 5 \text { to the Deck N } \\
\text { area.Queue }\end{array}$ & 0.00 & 0.00 & 0.00 & 0.00 & 0.00 & 0.00 \\
\hline $\begin{array}{l}\text { Deck N area to the Deck } \\
\text { 5.Queue }\end{array}$ & 0.00 & 0.00 & 0.00 & 0.00 & 0.00 & 0.00 \\
\hline $\begin{array}{l}\text { Drivers batching to shuttle } \\
\text { van.Queue }\end{array}$ & 21.0546 & 0.03 & 20.9303 & 21.1803 & 0.00 & 53.0115 \\
\hline Extenal ramp to area 1.Queue & 0.00 & 0.00 & 0.00 & 0.00 & 0.00 & 0.00 \\
\hline Extenal ramp to area 2.Queue & 0.00 & 0.00 & 0.00 & 0.00 & 0.00 & 0.00 \\
\hline Extenal ramp to area 3.Queue & 0.00 & 0.00 & 0.00 & 0.00 & 0.00 & 0.00 \\
\hline Extenal ramp to area 4.Queue & 0.00 & 0.00 & 0.00 & 0.00 & 0.00 & 0.00 \\
\hline Extenal ramp to Deck 5.Queue & 4.5364 & 0.14 & 3.9250 & 5.1700 & 0.00 & 26.2081 \\
\hline Count & \multicolumn{3}{|c|}{ Average } & $\begin{array}{l}\text { Minimum } \\
\text { Average }\end{array}$ & $\begin{array}{l}\text { Maximum } \\
\text { Average }\end{array}$ & \\
\hline Total loading time & & & 71.12 & 92869.00 & 93380.00 & \\
\hline
\end{tabular}

Figure 4: The simulation results for the current loading system. The longest waiting time was attributed to the batch delivery process, where drivers were collected by the shuttle van. The second-longest waiting time was attributed to the $5 \mathrm{~s}$ rule, which was applied to all vehicles to avoid collision with preceding vehicles. The total loading time was 93,099.70 s. As mentioned in Section 2.3.2, these results are similar to the actual data of port A.

TABLE 2: Results for AGV loading system scenario 1. The simulation results are reported in the same way as in Figure 4 and we tested 10-40 AGVs.

\begin{tabular}{lccc}
\hline $\begin{array}{l}\text { Number of AGVs } \\
\text { employed }\end{array}$ & $\begin{array}{c}\text { Total loading } \\
\text { time (s) }\end{array}$ & $\begin{array}{c}\text { Reduction rate for the loading time compared with the } \\
\text { previous }\end{array}$ & $\begin{array}{c}\text { Average waiting time within the } \\
\text { external } \begin{array}{c}\text { ramp } \\
(\mathrm{s})\end{array}\end{array}$ \\
\hline 10 & $267,469.00$ & -9.03 & 0.1728 \\
11 & $243,316.00$ & -8.30 & 0.2207 \\
12 & $223,131.00$ & -7.58 & 0.3075 \\
13 & $206,215.00$ & -7.06 & 0.3487 \\
14 & $191,658.00$ & -6.54 & 0.4306 \\
15 & $179,118.00$ & -6.17 & 0.5182 \\
16 & $168,065.00$ & -5.75 & 0.6281 \\
17 & $158,403.00$ & -5.46 & 0.7933 \\
18 & $149,761.00$ & -5.18 & 0.9676 \\
19 & $142,008.00$ & -4.79 & 1.1023 \\
20 & $135,208.00$ & -4.54 & 1.3167 \\
21 & $129,067.00$ & -4.34 & 1.6814 \\
22 & $123,464.00$ & -4.25 & 1.9076 \\
23 & $118,218.00$ & -3.87 & 2.0848 \\
24 & $113,642.00$ & -3.65 & 2.4887 \\
25 & $109,490.00$ & -3.53 & 2.9827 \\
26 & $105,628.00$ & -3.34 & 3.3725 \\
27 & $102,098.00$ & -2.76 & 4.2814 \\
28 & $99,278.00$ & & 5.7039 \\
\hline
\end{tabular}


TABLE 2: Continued.

\begin{tabular}{lccc}
\hline $\begin{array}{l}\text { Number of AGVs } \\
\text { employed }\end{array}$ & $\begin{array}{c}\text { Total loading } \\
\text { time }(\mathrm{s})\end{array}$ & $\begin{array}{c}\text { Reduction rate for the loading time compared with the } \\
\text { previous number of AGVs (\%) }\end{array}$ & $\begin{array}{c}\text { Average waiting time within the } \\
\text { external ramp (s) }\end{array}$ \\
\hline 29 & $96,806.00$ & -2.49 & 7.4914 \\
30 & $94,520.00$ & -2.36 & 9.3743 \\
31 & $92,593.00$ & -2.04 & 11.8527 \\
32 & $90,984.00$ & -1.74 & 14.9762 \\
33 & $89,737.00$ & -1.37 & 18.3850 \\
34 & $89,063.00$ & -0.75 & 23.2587 \\
35 & $88,376.00$ & -0.77 & 27.2625 \\
36 & $88,117.00$ & -0.29 & 32.9849 \\
37 & $87,877.00$ & -0.27 & 38.2575 \\
38 & $87,626.00$ & -0.29 & 43.9438 \\
39 & $87,475.00$ & -0.17 & 49.4631 \\
40 & $87,394.00$ & -0.09 & 54.4195 \\
\hline
\end{tabular}

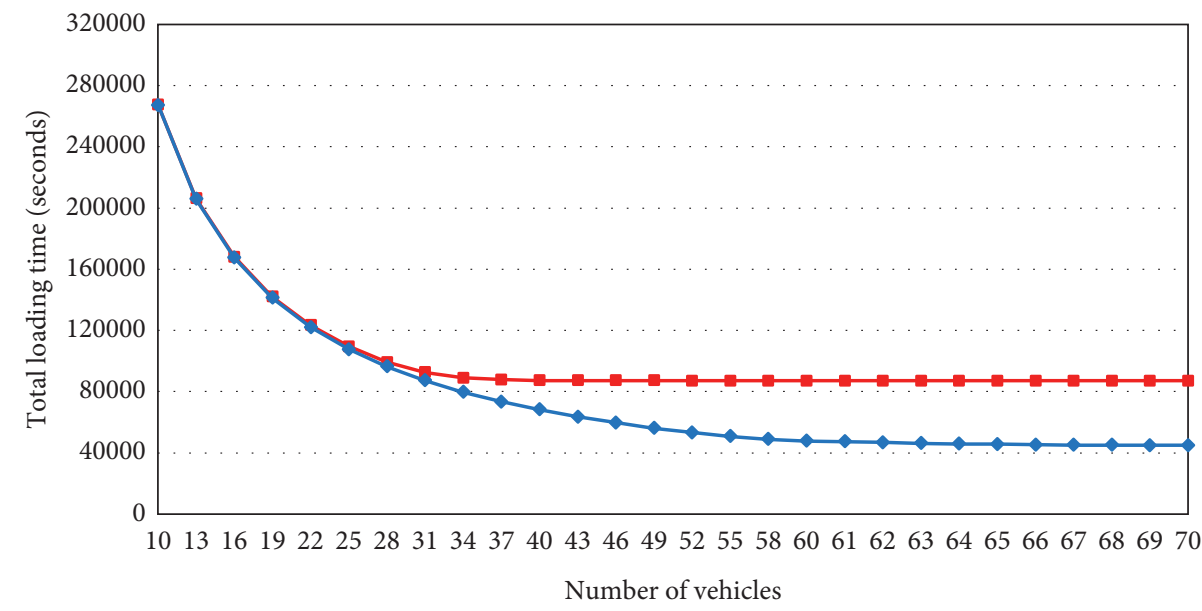

$\rightarrow$ Scenario 1

$\multimap$ Scenario 2

(a)

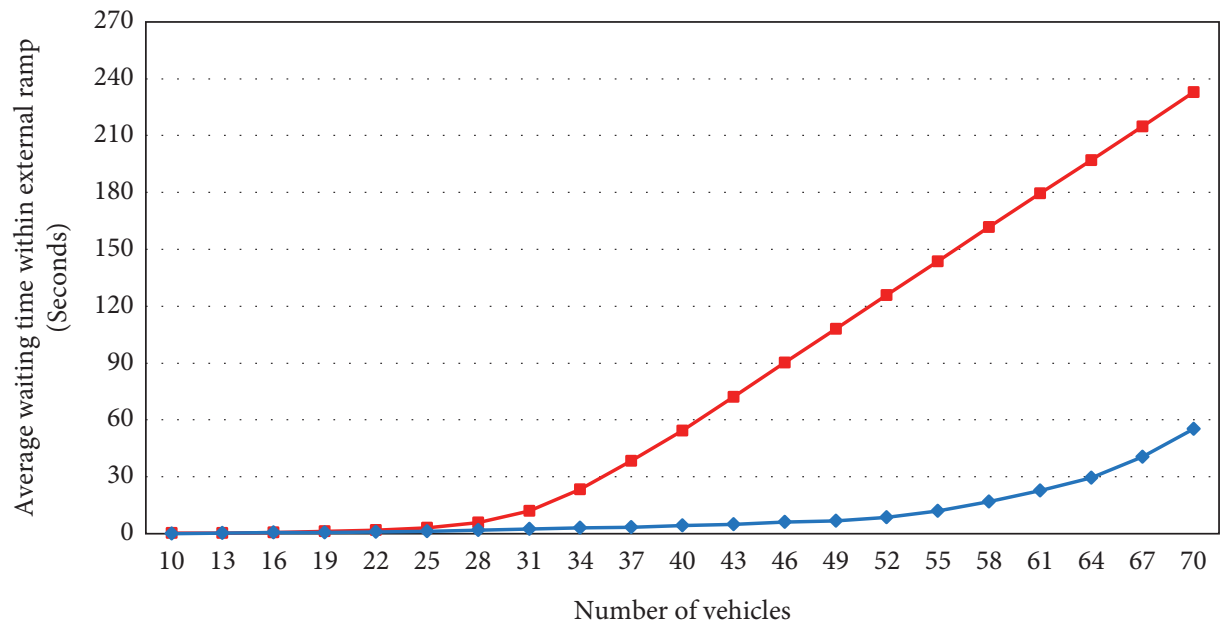

$\rightarrow$ Scenario 1

$\rightarrow$ Scenario 2

(b)

FIGURE 5: AGV loading system scenarios 1 and 2: (a) total loading time and (b) average waiting time within the external ramp. The difference between scenarios increased with the number of AGVs (source: author). 


\subsection{Cost Model Sensitivity Analysis}

3.2.1. Optimal Number of AGVs. To compare the total costs of the current and AGV loading systems, the minimum number of AGVs that matched the productivity of the current loading system was identified. With three gangs of stevedores, the current loading process takes $93,108.30 \mathrm{~s}$. The AGV loading process required a minimum of 29 AGVs following scenario 2 . Therefore, we considered the optimal number of AGVs to be 29 .

3.2.2. Cost Model Comparison. A cost model was developed to identify the economic benefits of AGVs compared with the current loading system (CLS). A robot generally has a life cycle of $80,000-100,000 \mathrm{~h}$, which is $10+$ years. The cost model was used to calculate the total operating costs of port A for a 15-year period with the optimal number of AGVs. The 15-year period was selected to consider the 10year lifetime of AGVs and another 5 years with new AGVs.

The first factor was the capital cost of the vehicles. For the AGV loading system, the vehicle capital cost accounted for a significant part of the total cost. At the time of submission, the cost of AGVs was not available. We assumed that the unit cost was approximately $€ 150,000$ based on expert speculation. This is a conservative estimate, and actual AGVs are not expected to cost as much. For the current loading system, the main capital costs are for people and the shuttle van. The capital cost for the van was set to $€ 114,000$, and the capital costs of the drivers were calculated in terms of wages. To consider vehicle failure and a charge rotation, the minimum number of AGVs was increased $20 \%$ to include six additional AGVs as spare.

The total energy costs of the current and AGV loading systems differed because they consumed different types of energy. The shuttle van was powered by diesel, whereas the AGVs use electricity. In addition, they consume different amounts of energy because they have different total travel distances. The total energy costs of the shuttle vans and AGVs per loading process were calculated as follows:

$$
\begin{aligned}
E_{\mathrm{van}} & =\frac{t_{\mathrm{van}} \times D l_{\mathrm{van}}}{100} \times p_{d}, \\
E_{\mathrm{AGV}} & =\frac{t_{\mathrm{AGV}} \times E l_{\mathrm{AGV}}}{100} \times p_{\mathrm{kwh}},
\end{aligned}
$$

where $D l_{\text {van }}$ is the liters of diesel consumed per $100 \mathrm{~km}$ travelled by the van, $E l_{\mathrm{AGV}}$ is the electricity consumed per $100 \mathrm{~km}$ travelled by the AGVs, $p_{d}$ is the price per litre of diesel, and $p_{\mathrm{kwh}}$ is the price per kilowatt-hour of electricity. $t_{\mathrm{van}}$ is the travel distance $(\mathrm{km})$ of the van, $t_{\mathrm{AGV}}$ is the travel distance $(\mathrm{km})$ of the AGVs, $E_{\mathrm{van}}$ is the total energy cost of the van, and $E_{\mathrm{AGV}}$ is the total energy cost of the AGVs for each loading process.

The next intermediate parameter is the costs for workers' wages. The annual salary can be calculated by multiplying the wages per loading process with the number of loading processes per year. The wages per loading process were calculated as follows:

$$
\begin{aligned}
W_{s v d} & =p_{s v d} \times h, \\
W_{\mathrm{AGV}} & =p_{o p} \times h,
\end{aligned}
$$

where $h$ is the total working hours per loading process of the $7352 \mathrm{R} / \mathrm{T}$ size vessel, $p_{s v d}$ is the hourly pay for a stevedore, $p_{\mathrm{AGV}}$ is the hourly pay for an AGV operator, $W_{s v d}$ is the total wages for stevedores per loading process, and $W_{\mathrm{AGV}}$ is the total wages for AGV operators per loading process. The aforementioned intermediate parameters can be used to calculate the annual operating costs of the current and AGV loading systems. We calculated the annual salaries for workers and annual energy costs for vehicles as follows:

$$
O_{0}^{\text {cls }}=n_{s} \times\left\{E_{\text {van }}+\left(W_{\text {svd }} \times n_{\text {svd }} \times n_{\text {gang }}\right)\right\}+\left(s_{\text {van }} \times n_{\text {van }}\right) \text {, }
$$

$\mathrm{O}_{0}^{\mathrm{AGV}}=E_{\mathrm{AGV}}+\left(W_{o p} \times n_{o p}\right) \times n_{s}+s_{\mathrm{AGV}} \times T_{\mathrm{AGV}}$,

where $n_{s}$ is the number of loading processes per year, $n_{\text {svd }}$ is the number of stevedores, $n_{\text {gang }}$ is the number of gangs, $T_{\mathrm{AGV}}$ is the total number of AGVs $=n_{\mathrm{AGV}}+n_{\mathrm{AGV} \text {-spare }}, s_{\mathrm{van}}$ is the total service cost per van, and $s_{\mathrm{AGV}}$ is the total service cost per AGV. The operating costs for the 15 -year period were calculated from year 0 and with the inflation rate $\mathrm{I}$ :

$$
O_{t}=O_{0} \times(1+I)^{t} ; 1 \leq t \leq 15 .
$$

The vehicle capital costs in year 0 were calculated as follows:

$$
\begin{aligned}
C_{0}^{\mathrm{cls}} & =p_{\mathrm{van}} \times n_{\mathrm{van}} ; 1 \leq t \leq 15, \\
C_{0}^{\mathrm{AGV}} & =T_{\mathrm{AGV}} \times\left\{p_{\mathrm{AGV}}+c_{\mathrm{st}}+\left(L l_{r} \times s a c_{\mathrm{st}}\right)\right\}, \quad 1 \leq t \leq 15,
\end{aligned}
$$

where $p_{\text {van }}$ is the price per shuttle van, $p_{\mathrm{AGV}}$ is the price per $\mathrm{AGV}, L l_{r}$ is the land lease rate per square metre, $s a c_{\mathrm{st}}$ is the surface area per charging station, and $c_{\mathrm{st}}$ is the cost of the charging station and parking garage. The capital costs for the AGVs include the costs for the charging facilities. The capital costs of the vehicles for the 15 -year period were calculated as follows:

$$
\begin{aligned}
C_{t}^{\mathrm{cls}} & =\left\{\begin{array}{l}
C_{0} \times(1+I)^{t}, \text { if } t=10, \\
0, \text { otherwise, }
\end{array}\right. \\
C_{t}^{\mathrm{AGV}} & =\left\{\begin{array}{l}
C_{0} \times(1+I)^{t}, \text { if } t=10, \\
\left(L l_{r} \times s a c_{s t} \times T_{\mathrm{AGV}}\right) \times I^{t},
\end{array}\right.
\end{aligned}
$$

Vehicles were assumed to have a lifespan of 10 years. $R_{t}^{\mathrm{cls}}$ is the total cash flow of the current loading system in year $t$, and $R_{t}^{A G V}$ is the total cash flow of the AGV loading system in year $t$. The total cash flow of year $t$ is the summation of the operating cash flow and vehicle capital cost: 
TABle 3: Parameters of the cost model and their values.

\begin{tabular}{|c|c|c|c|}
\hline Parameter description & Symbol & Unit & Value \\
\hline Litres of diesel consumed per $100 \mathrm{~km}$ by the van & $D l_{\text {van }}$ & $1 \mathrm{~L} / 100 \mathrm{~km}$ & 12 \\
\hline Electricity consumed per $100 \mathrm{~km}$ by the AGVs & $E l_{\mathrm{AGV}}$ & $1 \mathrm{kwh} / 100 \mathrm{~km}$ & 20 \\
\hline Price per litre of diesel & $p_{d}$ & $€ / \mathrm{L}$ & 1.24 \\
\hline Price per kilowatt-hour of electricity & $p_{\mathrm{kwh}}$ & $€ / \mathrm{kwh}$ & 0.25 \\
\hline Travel distance for a van per loading process & $t_{\mathrm{van}}$ & $\mathrm{km}$ & 590 \\
\hline Travel distance by AGVs per loading process & $t_{\mathrm{AGV}}$ & $\mathrm{km}$ & 4720 \\
\hline Total working hours per loading process & $h$ & $\mathrm{~h}$ & 26 \\
\hline Hourly pay for a stevedore & $p_{\text {svd }}$ & $€ / h$ & 19 \\
\hline Hourly pay for an AGV operator & $p_{\mathrm{AGV}}$ & $€ / \mathrm{h}$ & 19 \\
\hline Number of loading processes per year & $n_{s}$ & - & 120 \\
\hline Number of stevedores & $n_{\text {svd }}$ & Person & 16 \\
\hline Number of gangs & $n_{\text {gang }}$ & Group & 3 \\
\hline Total number of AGVs & $T_{\mathrm{AGV}}^{\mathrm{gang}}$ & Vehicle & 35 \\
\hline Number of AGVs in operation & $n_{\mathrm{AGV}}$ & Vehicle & 29 \\
\hline Number of spare AGVs & $n_{\mathrm{AGV}-\text { spare }}$ & Vehicle & 6 \\
\hline Total service cost per van for a year & $s_{\text {van }}$ & $€ /$ year & 1000 \\
\hline Total service cost per AGV for a year & $s_{\mathrm{AGV}}$ & $€ /$ year & 1000 \\
\hline Price per shuttle van & $p_{\text {van }}$ & $€ /$ vehicle & 150,000 \\
\hline Price per AGV & $p_{\mathrm{AGV}}$ & $€ /$ vehicle & 38,000 \\
\hline Land lease rate per square metre & $L l_{r}$ & $€ / \mathrm{m}^{2}$ & 15 \\
\hline Surface area per charging station & $\mathrm{sac}_{\mathrm{st}}$ & $\mathrm{m}^{2}$ & 30 \\
\hline $\mathrm{CO}_{2}$ emissions from a vehicle per kilometre & $\mathrm{CO}_{2}^{\mathrm{car}}$ & $\mathrm{g}$ & 224 \\
\hline $\mathrm{CO}_{2}$ emissions from the van per kilometre & $\mathrm{Co}_{2}^{\mathrm{van}}$ & $\mathrm{g}$ & 50 \\
\hline $\mathrm{CO}_{2}$ emissions from an AGV per kilometre & $\mathrm{CO}_{2}^{\mathrm{AGV}}$ & $\mathrm{g}$ & 230 \\
\hline $\mathrm{CO}_{2}$ price per tonne & $\mathrm{CO}_{2} \mathrm{pr}$ & $€ / t$ & 50 \\
\hline Cost of the charging station and parking garage & $c_{\text {st }}$ & Station & 5,000 \\
\hline
\end{tabular}

$$
\begin{aligned}
R_{t}^{\mathrm{cls}} & =\mathrm{co}_{2 t}^{\mathrm{cls}}+C_{t}^{\mathrm{cls}}, \\
R_{t}^{\mathrm{AGV}} & =\mathrm{co}_{2 t}^{\mathrm{AGV}}+C_{t}^{\mathrm{AGV}} .
\end{aligned}
$$

To extend the cost model analysis to an environmental perspective, the cost of $\mathrm{CO}_{2}$ emissions was considered. We calculated the $\mathrm{CO}_{2}$ emissions from the vehicles and converted them to monetary values. The $\mathrm{CO}_{2}$ emissions from the current loading system are mainly from the operation of vehicles and the van. In contrast, the $\mathrm{CO}_{2}$ emissions from AGV operation were zero, but the emissions from electricity production needed to be considered. Holmberg and Ali [42] calculated the $\mathrm{CO}_{2}$ emissions from the internal combustion engine and electric vehicles per kilometre. Their work was used to calculate the total $\mathrm{CO}_{2}$ emissions from the two loading systems:

$$
\begin{aligned}
\text { emiss }^{\mathrm{cls}} & =\left(\mathrm{co}_{2}^{\mathrm{car}} \times t_{\mathrm{car}}\right)+\left(\mathrm{co}_{2}^{\mathrm{car}} \times t_{\mathrm{van}}\right), \\
\text { emiss }^{\mathrm{AGV}} & =\mathrm{co}_{2}^{\mathrm{AGV}} \times t_{\mathrm{AGV}},
\end{aligned}
$$

where $\mathrm{CO}_{2}^{\text {car }}$ is the $\mathrm{CO}_{2}$ emissions from a vehicle per kilometer, $\mathrm{Co}_{2}^{\text {van }}$ is the $\mathrm{CO}_{2}$ emissions from the van per kilometer, $\mathrm{Co}_{2}^{\mathrm{AGV}}$ is the $\mathrm{CO}_{2}$ emissions from an $\mathrm{AGV}$ per kilometer given that the electricity generation mix is coal, emiss ${ }^{c l p}$ is the total $\mathrm{CO}_{2}$ emissions produced by the current loading system, emiss ${ }^{\mathrm{AGV}}$ is the total $\mathrm{CO}_{2}$ emissions produced by the AGV loading system, and $t_{\text {car }}$ is the travel distance of vehicles per loading process.

The estimated $\mathrm{CO}_{2}$ price has varied greatly as climate change has become an increasing concern [43]. Recent studies on $\mathrm{CO}_{2}$ abatement have estimated the average $\mathrm{CO}_{2}$ price to be $€ 40-€ 70[44,45]$. The intermediate parameters in equations (14) and (15) can be used to calculate the total $\mathrm{CO}_{2}$ costs per year with the two loading systems:

$$
\begin{aligned}
\mathrm{co}_{2} \mathrm{cst}_{0}^{\mathrm{cls}} & =\frac{\mathrm{EM}^{\mathrm{cls}} \times n_{s}}{1 \mathrm{mt}} \times \mathrm{co}_{2} \mathrm{pr}, \\
\mathrm{co}_{2} \mathrm{cst}_{0}^{\mathrm{AGV}} & =\frac{\mathrm{EM}^{\mathrm{AGV}} \times n_{s}}{1 \mathrm{mt}} \times \mathrm{co}_{2} \mathrm{pr},
\end{aligned}
$$

where $\mathrm{CO}_{2} \mathrm{pr}$ is the $\mathrm{CO}_{2}$ price per metric tonne. Then, the total $\mathrm{CO}_{2}$ costs for the next 15 years can be calculated as follows:

$$
\begin{aligned}
\mathrm{co}_{2} \mathrm{cst}_{t}^{\mathrm{cls}} & =\mathrm{co}_{2} \mathrm{cst}_{0}^{\mathrm{cls}} \times(1+r)^{t}, 1 \leq t \leq 15, \\
\mathrm{co}_{2} \mathrm{cst}_{t}^{\mathrm{AGV}} & =\mathrm{co}_{2} \mathrm{cst}_{0}^{\mathrm{AGV}} \times(1+r)^{t}, 1 \leq t \leq 15 .
\end{aligned}
$$

The discount rate $r$ was included because analysts forecast the $\mathrm{CO}_{2}$ price to rise in the future [46]. Tables 3 and 4 present the values of the initial and intermediate parameters used in the cost model. The intermediate parameters were calculated using equations (1)-(4) and (14)-(17). Table 5 presents the cash flows for the 15-year period as calculated using equations (5)-(13).

Figure 6 compares the cash flows in each year for the current and AGV loading systems. In year 0 , the AGV loading system had higher costs than the current loading system because of the initial capital costs of the AGVs. In year 1, the AGV loading system had a much lower operating cost than the current loading system. The main difference 
TABLE 4: Intermediate parameters calculated using equations (1)-(4), (14) and (15).

\begin{tabular}{|c|c|c|c|}
\hline Parameter description & Symbol & Unit & Value \\
\hline Total energy cost of van per loading process & $E_{\mathrm{van}}$ & $€$ & 95 \\
\hline Total energy cost of AGVs per loading process & $E_{\mathrm{AGV}}$ & $€$ & 236 \\
\hline Total wages for stevedores per loading process & $W_{\text {svd }}$ & $€$ & 494 \\
\hline Total wages for AGV operators per loading process & $W_{\mathrm{AGV}}$ & $€$ & 494 \\
\hline Total $\mathrm{CO}_{2}$ emissions produced from the current loading system per loading process & emiss $^{\mathrm{cls}}$ & g & 664,340 \\
\hline Total $\mathrm{CO}_{2}$ emissions from the AGV loading system per loading process & emiss $^{\text {AGV }}$ & g & 236,000 \\
\hline
\end{tabular}

Table 5: Cash flows for the AGV and current loading systems. These cash flows were calculated using equations (5)-(13) in euros (€).

\begin{tabular}{|c|c|c|c|c|c|c|}
\hline \multirow{2}{*}{$T$} & \multicolumn{3}{|c|}{ Current loading system } & \multicolumn{3}{|c|}{ AGV loading system } \\
\hline & $O_{t}^{\mathrm{cls}}$ & $C_{t}^{\mathrm{cls}}$ & $R_{t}^{\mathrm{cls}}$ & $\mathrm{O}_{t}^{\mathrm{AGV}}$ & $C_{t}^{\mathrm{AGV}}$ & $R_{t}^{\mathrm{AGV}}$ \\
\hline 0 & $2,859,840$ & 114,000 & $2,973,840$ & 241,160 & $5,440,750$ & $5,681,910$ \\
\hline 1 & $2,917,037$ & 0 & $2,917,037$ & 245,983 & 16,065 & 262,048 \\
\hline 2 & $2,975,378$ & 0 & $2,975,378$ & 250,903 & 16,386 & 267,289 \\
\hline 3 & $3,034,885$ & 0 & $3,034,885$ & 255,921 & 16,714 & 272,635 \\
\hline 4 & $3,095,583$ & 0 & $3,095,583$ & 261,039 & 17,048 & 278,088 \\
\hline 5 & $3,157,494$ & 0 & $3,157,494$ & 266,260 & 17,389 & 283,649 \\
\hline 6 & $3,220,644$ & 0 & $3,220,644$ & 271,585 & 17,737 & 289,322 \\
\hline 7 & $3,285,057$ & 0 & $3,285,057$ & 277,017 & 18,092 & 295,109 \\
\hline 8 & $3,350,758$ & 0 & $3,350,758$ & 282,557 & 18,454 & 301,011 \\
\hline 9 & $3,417,774$ & 0 & $3,417,774$ & 288,209 & 18,823 & 307,031 \\
\hline 10 & $3,486,129$ & 138,965 & $3,625,094$ & 293,973 & $6,826,443$ & $7,120,416$ \\
\hline 11 & $3,555,852$ & 0 & $3,555,852$ & 299,852 & 19,583 & 319,435 \\
\hline 12 & $3,626,969$ & 0 & $3,626,969$ & 305,849 & 19,975 & 325,824 \\
\hline 13 & $3,699,508$ & 0 & $3,699,508$ & 311,966 & 20,374 & 332,340 \\
\hline 14 & $3,773,498$ & 0 & $3,773,498$ & 318,205 & 20,782 & 338,987 \\
\hline 15 & $3,848,968$ & 0 & $3,848,968$ & 324,570 & 21,197 & 345,767 \\
\hline
\end{tabular}

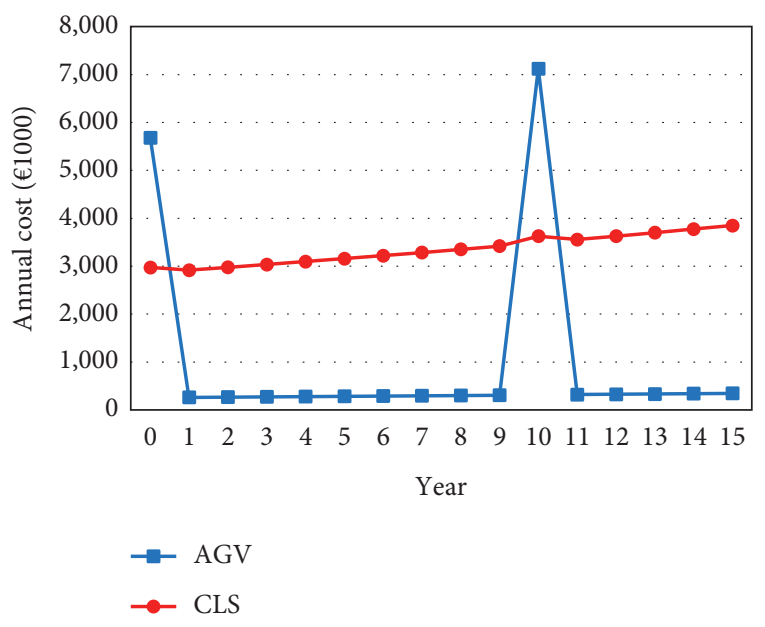

(a)

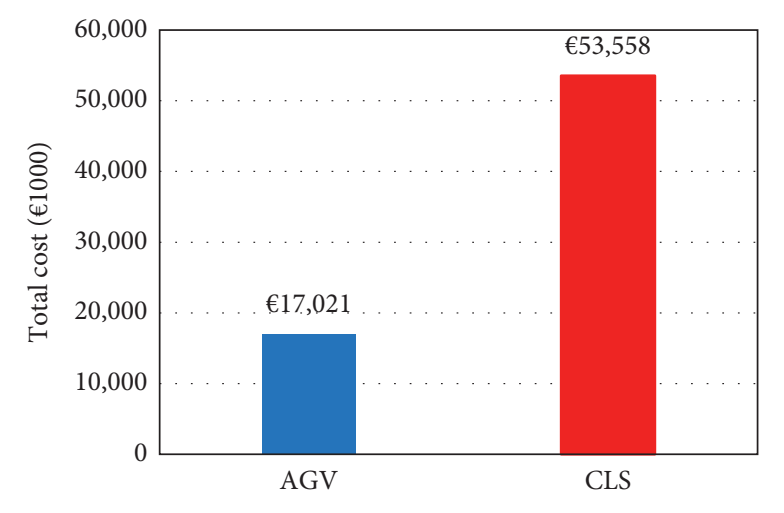

(b)

FIGURE 6: Total operating costs for the current and AGV loading systems: (a) each year and (b) for a 15-year period (source: author).

was attributed to the costs of wages. Although AGVs need some operators to control the system, they replace a significant part of the human resources required by the current loading system. In year 10, the AGV loading system sees another increase in cost, because new vehicles are purchased. Over the 15-year period, the total cash flows for the current and AGV loading systems were $€ 53,558,339$ and
$€ 17,021,863$, respectively. The total cash flow for the AGV loading system was almost three times less than that for the current loading system despite the initial capital costs for vehicles.

Figure 7 demonstrates the environmental impact of using AGVs. To clarify the environmental benefit, the monetary value of $\mathrm{CO}_{2}$ emissions was not included in the 


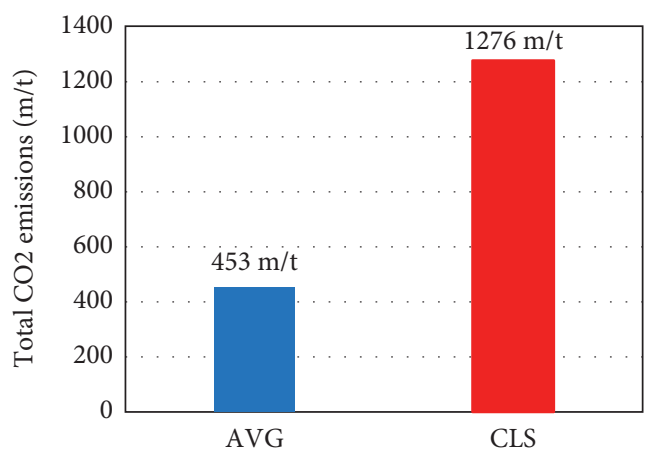

(a)

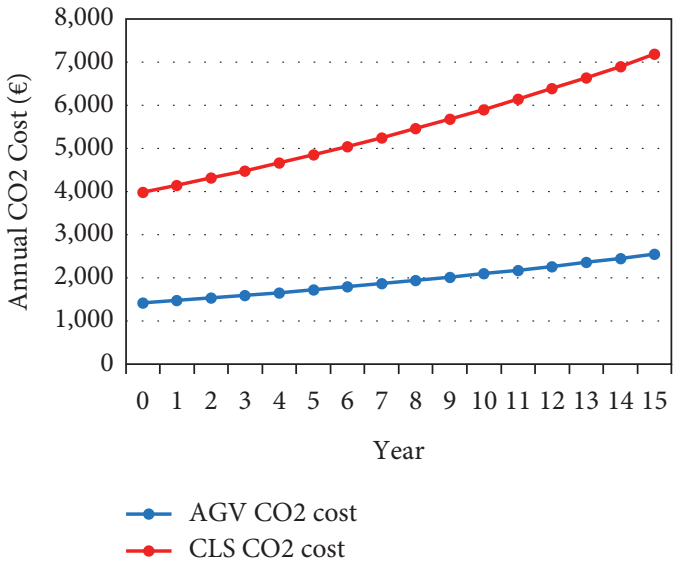

(b)

Figure 7: (a) Total $\mathrm{CO}_{2}$ emissions from the current and AGV loading systems for a 15-year period and (b) $\mathrm{CO}_{2}$ emission costs of the current and AGV loading systems each year (source: author).

operating costs but was shown separately. Over the 15year period, the total $\mathrm{CO}_{2}$ emissions from the current and AGV loading systems were 1276 and $453 \mathrm{~m}^{3} / \mathrm{t}$, respectively. These values are equivalent to $€ 86,993$ and $€ 30,904$, respectively. These results show that the AGV loading system can be operated at a much lower cost than the current loading process and also has great environmental benefits.

\section{Conclusions}

We proposed automating the operation of RORO terminals by using AGVs to reduce human factors and improve performance. The impact of using AGVs was investigated in terms of productivity, cost efficiency, and environmental impact. A series of simulation models were developed, and a sensitivity analysis was performed to optimize the number of AGVs. A cost model was developed to analyse the economic benefits of the AGV loading system with the optimal number of AGVs compared with those of the current loading system. For a 15-year period, the total cost of the AGV loading system was almost three times less than that of the current loading system. Finally, the environmental impact of the AGV loading system was estimated in terms of $\mathrm{CO}_{2}$ emissions and demonstrated to be significantly less than that of the current loading system.

This study has some limitations. First, we only tested one type of vessel (i.e., Glovis Splendor). However, there are many different ships of different sizes, so the dispatch strategy of AGVs and their optimal number may differ. Also, the actual size of the cars to be loaded differs from the standard size vehicle which we tested here, so the total number of vehicles that can be loaded probably differs from the nominal vehicle carrying capacity [15]. To implement AGVs in the real world, the type of vessels may be needed to classify AGV dispatch strategies, and the study must be developed to be applied to more varying vehicles. Therefore, further case studies need to be tested. Second, costs incurred by vessels at the port were not included in the cost model and environmental impact analysis. Indeed, vessels incur much higher costs at ports than at sea, and emissions released by vessels at port are a continuing concern $[47,48]$. Regardless of the vehicle capital costs and efficiency, the most effective cost reduction strategy may be minimizing the loading time. Third, more sophisticated vehicle dispatch/schedule strategies can be considered in the future. Developing a more effective schedule to release vehicles to the vessel can reduce the waiting time and improve the port performance. We may investigate these topics in the future and present our results in subsequent papers. To the best of our knowledge, we are the first group to propose automating RORO terminal operation with AGV technology. Our study demonstrated that the potential impact is significant, so AGVs are expected to become a good alternative option in the future for addressing labour shortages and the "untact" era.

\section{Data Availability}

The data used to support the findings of this study are included within the article.

\section{Conflicts of Interest}

No potential conflicts of interest were reported by the authors.

\section{Authors' Contributions}

Conceptualization was done by S.K. and S.P.; methodology was done by S.P.; validation was done by S.P. and J.H.; formal analysis was done by S.P.; data curation was done by S.P. and J.H.; original draft preparation was done by S.P.; reviewing and editing were done by S.Y. and S.K.; visualization was done by S.P., S.Y., and J.H.; supervision was done by S.K.; project administration was done by S.K.; funding acquisition was done by S.K. All authors have read and agreed to the published version of the manuscript. 


\section{Acknowledgments}

This work was supported by the National Research Foundation of Korea (NRF) grant funded by the Korea Government (MSIT) (no. NRF-2019R1G1A1087736).

\section{References}

[1] J. S. Park and Y. J. Seo, "The impact of seaports on the regional economies in South Korea: panel evidence from the augmented Solow model," Transportation Research Part E: Logistics and Transportation Review, vol. 85, pp. 107-119, 2016.

[2] Z. H. Munim and H. J. Schramm, "The impacts of port infrastructure and logistics performance on economic growth: the mediating role of seaborne trade," Journal of Shipping and Trade, vol. 3, no. 1, pp. 1-19, 2018.

[3] S. Kim, D. Kang, and J. Dinwoodie, "Competitiveness in a multipolar port system: striving for regional gateway status in NorthEast Asia," The Asian Journal of Shipping and Logistics, vol. 32, no. 2, pp. 119-125, 2016.

[4] A. C. Orive, J. I. P. Santiago, M. M. E. Corral, and N. González-Cancelas, "Strategic analysis of the automation of container port terminals through BOT (business observation tool)," Logistics, vol. 4, no. 1, pp. 1-13, 2020.

[5] A. M. Martín-Soberón, A. Monfort, R. Sapiña, N. Monterde, and D. Calduch, "Automation in port container terminals," Procedia - Social and Behavioral Sciences, vol. 160, pp. 195204, 2014.

[6] H. Dkhil, I. Diarrassouba, S. Benmansour, and A. Yassine, "Modelling and solving a berth allocation problem in an automotive transshipment terminal," Journal of the Operational Research Society, vol. 72, no. 3, pp. 580-593, 2021.

[7] E. Kara, "Analysis of accidents at the quayside operations in the Turkish port," International Journal of Renewable Energy Technology, vol. 5, no. 3, pp. 1-5, 2016.

[8] B. P. Abbott, R. Abbott, T. D. Abbott, and M. R. Abernathy, "Observation of gravitational waves from a binary black hole merger," Physical Review Letters, vol. 116, no. 6, Article ID 061102, 2016.

[9] J. S. L. Lam and T. Notteboom, "The greening of ports: a comparison of port management tools used by leading ports in asia and europe," Transport Reviews, vol. 34, no. 2, pp. 169-189, 2014.

[10] N. Bahnes, B. Kechar, and H. Haffaf, "Cooperation between Intelligent Autonomous Vehicles to enhance container terminal operations," Journal of Innovation in Digital Ecosystems, vol. 3, no. 1, pp. 22-29, 2016.

[11] G. Fragapane, R. de Koster, F. Sgarbossa, and J. O. Strandhagen, "Planning and control of autonomous mobile robots for intralogistics: literature review and research agenda," European Journal of Operational Research, vol. 294, no. 2, pp. 405-426, 2021.

[12] A. Motroni, A. Buffi, P. Nepa, and B. Tellini, "Sensor-Fusion and tracking method for indoor vehicles with low-density UHF-rfid tags," IEEE Transactions on Instrumentation and Measurement, vol. 11, no. 70, pp. 1-14, 2021.

[13] T. A. Tamba, B. Hong, and K.-S. Hong, "A path following control of an unmanned autonomous forklift," International Journal of Control, Automation and Systems, vol. 7, no. 1, pp. 113-122, 2009.

[14] L. Blain, "Autonomous robot valet parking is coming to Gatwick Airport,” 2019, https://newatlas.com/stanleyrobotics-stan-robot-parking-valet/58204/.
[15] S. Park, J. Hwang, H. Yang, and S. Kim, "Simulation modelling for automated guided vehicle introduction to the loading process of ro-ro ships," Journal of Marine Science and Engineering, vol. 9, no. 4, p. 441, 2021.

[16] P. Morales-Fusco, S. Saurí, and B. Spuch, "Quality indicators and capacity calculation for RoRo terminals," Transportation Planning and Technology, vol. 33, no. 8, pp. 695-717, 2010.

[17] H. Y. Kim, "A comparative analysis of the efficiency of automobile export Ports in Korea and Japan," Journal of Korea Port Economic Association, vol. 33, no. 33, pp. 73-81, 2017.

[18] K. Tam, R. Hopcraft, T. Crichton, and K. Jones, "The potential mental health effects of remote control in an autonomous maritime world," Journal of International Maritime Safety, Environmental Affairs, and Shipping, vol. 5, no. 2, pp. 40-55, 2021.

[19] A. Corominas, A. Lusa, and R. Pastor, "Planning annualised hours with a finite set of weekly working hours and crosstrained workers," European Journal of Operational Research, vol. 176, no. 1, pp. 230-239, 2007.

[20] M. Collewet and J. Sauermann, "Working hours and productivity," Labour Economics, vol. 47, pp. 96-106, 2017.

[21] Y. Keceli, S. Aksoy, and Y. V. Aydogdu, "A simulation model for decision support in Ro-Ro terminal operations," International Journal of Logistics Systems and Management, vol. 15, no. 4, pp. 338-358, 2013.

[22] J. J. D. Hernández, E. M. Budría, and S. J. Díaz, "The economic efficiency in stevedoring determinants industry," International Journal of Transport Economics, vol. 39, no. 3, pp. 369-396, 2012.

[23] P. Antão, M. Calderón, M. Puig, A. Michail, C. Wooldridge, and R. M. Darbra, "Identification of occupational health, safety, security (OHSS) and environmental performance indicators in port areas," Safety Science, vol. 85, pp. 266-275, 2016.

[24] Y. Wang, S. Zhan, Y. Liu, and Y. Li, "Occupational hazards to health of port workers," International Journal of Occupational Safety and Ergonomics, vol. 23, no. 4, pp. 584-588, 2017.

[25] A. A. Shikdar and N. M. Sawaqed, "Worker productivity, and occupational health and safety issues in selected industries," Computers \& Industrial Engineering, vol. 45, no. 4, pp. 563$572,2003$.

[26] J. He, H. Liu, and A. Salvo, "Severe air pollution and labor productivity: evidence from industrial towns in China," American Economic Journal: Applied Economics, vol. 11, no. 1, pp. 173-201, 2019.

[27] M. Pereira, T. Comans, G. Sjøgaard et al., "The impact of workplace ergonomics and neck-specific exercise versus ergonomics and health promotion interventions on office worker productivity: a cluster-randomized trial," Scandinavian Journal of Work, Environment \& Health, vol. 45, no. 1, pp. 42-52, 2019.

[28] W. Karwowski, M. Rahimi, and T. Mihaly, "Effects of computerized automation and robotics on safety performance of a manufacturing plant," Journal of Occupational Accidents, vol. 10, no. 3, pp. 217-233, 1988.

[29] S. S. Kamaruddin, M. F. Mohammad, and R. Mahbub, "Barriers and impact of mechanisation and automation in construction to achieve better quality products," Procedia Social and Behavioral Sciences, vol. 222, pp. 111-120, 2016.

[30] R. Macrorie, S. Marvin, and A. While, "Robotics and automation in the city: a research agenda," Urban Geography, vol. 42, no. 2, pp. 1-21, 2019.

[31] E. Demirci, "Simulation modelling and analysis of a port investment," SIMULATION, vol. 79, no. 2, pp. 94-105, 2003. 
[32] D. Muravev, S. Aksoy, A. Rakhmangulov, and V. Aydogdu, "Comparing model development in discrete event simulation on Ro-Ro terminal example," International Journal of Logistics Systems and Management, vol. 24, pp. 283-297, 2016.

[33] D. M. Todorrov, Ro-Ro Handbook: A Practical Guide to Roll-On Roll-Off Cargo Ships, schiffer publishing, Atglen, PA USA, 2016.

[34] M. Kotachi, G. Rabadi, and M. F. Obeid, "Simulation modeling and analysis of complex port operations with multimodal transportation," Procedia Computer Science, vol. 20, pp. 229-234, 2013.

[35] F. V. Rusca, P. Mihaela, R. Eugen, and A. R. Mircea, "Simulation model for maritime container terminal," Transport Problems, vol. 13, no. 4, pp. 47-54, 2018.

[36] A. Cartenì and S. d. Luca, "Tactical and strategic planning for a container terminal: modelling issues within a discrete event simulation approach," Simulation Modelling Practice and Theory, vol. 21, no. 1, pp. 123-145, 2012.

[37] S. Islam, "Simulation of truck arrival process at a seaport: evaluating truck-sharing benefits for empty trips reduction," International Journal of Logistics Research and Applications, vol. 24, no. 1, pp. 94-112, 2018.

[38] V. D. Nguyen and K. H. Kim, "A dispatching method for automated lifting vehicles in automated port container terminals," Computers \& Industrial Engineering, vol. 56, no. 3, pp. 1002-1020, 2009.

[39] D. Pjevčević, I. Vladisavljević, K. Vukadinović, and D. Teodorović, "Application of DEA to the analysis of AGV fleet operations in a port container terminal," Procedia-Social and Behavioral Sciences, vol. 20, pp. 816-825, 2011.

[40] S. Kavakeb, T. T. Nguyen, K. McGinley, Z. Yang, I. Jenkinson, and R. Murray, "Green vehicle technology to enhance the performance of a European port: a simulation model with a cost-benefit approach," Transportation Research Part C: Emerging Technologies, vol. 60, pp. 169-188, 2015.

[41] G. A. Kumar, J. H. Lee, J. Hwang, and J. Park, "LiDAR and camera fusion approach for object distance estimation in selfdriving vehicles," Symmetry, vol. 12, no. 2, pp. 1-23, 2020.

[42] K. Holmberg and A. Erdemir, "The impact of tribology on energy use and $\mathrm{CO}_{2}$ emission globally and in combustion engine and electric cars," Tribology International, vol. 135, pp. 389-396, 2019.

[43] M. Barnett, W. Brock, and L. P. Hansen, "Pricing uncertainty induced by climate change," Review of Financial Studies, vol. 33, no. 3, pp. 1024-1066, 2020.

[44] B. Bakhtyar, Y. Ibrahim, M. A. Alghoul, N. Aziz, A. Fudholi, and $\mathrm{K}$. Sopian, "Estimating the $\mathrm{CO}_{2}$ abatement cost: substitute price of avoiding $\mathrm{CO}_{2}$ emission (SPAE) by renewable Energy's feed in tariff in selected countries," Renewable and Sustainable Energy Reviews, vol. 35, pp. 205-210, 2014.

[45] S. Poelhekke, "How expensive should $\mathrm{CO}_{2}$ be? Fuel for the political debate on optimal climate policy," Heliyon, vol. 5, no. 11, Article ID e02936, 2019.

[46] R. G. Haight, R. Bluffstone, J. D. Kine, and J. W. Coulston, "Estimating the present value of carbon sequestration in U.S. Forests, 2015-2050, for evaluating federal climate change mitigation policies," Agricultural \& Resource Economics Review, vol. 49, no. 1, pp. 150-177, 2020.

[47] M. Tichavska and B. Tovar, "Environmental cost and ecoefficiency from vessel emissions in las Palmas Port," Transportation Research Part E: Logistics and Transportation Review, vol. 83, pp. 126-140, 2015.

[48] A. De, A. Choudhary, M. Turkay, and M. K. Tiwari, "Bunkering policies for a fuel bunker management problem for liner shipping networks," European Journal of Operational Research, vol. 289, no. 3, pp. 927-939, 2021. 